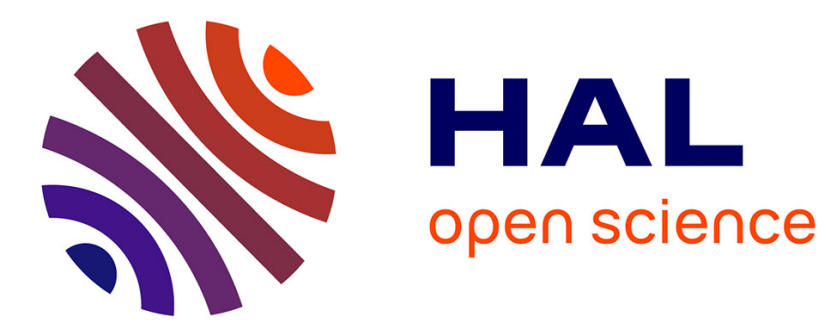

\title{
Patterned vegetation and rainfall intermittency
}

\author{
A.Y. Kletter, J. von Hardenberg, E. Meron, A. Provenzale
}

\section{To cite this version:}

A.Y. Kletter, J. von Hardenberg, E. Meron, A. Provenzale. Patterned vegetation and rainfall intermittency. Journal of Theoretical Biology, 2009, 256 (4), pp.574. 10.1016/j.jtbi.2008.10.020 . hal00554522

\section{HAL Id: hal-00554522 \\ https://hal.science/hal-00554522}

Submitted on 11 Jan 2011

HAL is a multi-disciplinary open access archive for the deposit and dissemination of scientific research documents, whether they are published or not. The documents may come from teaching and research institutions in France or abroad, or from public or private research centers.
L'archive ouverte pluridisciplinaire HAL, est destinée au dépôt et à la diffusion de documents scientifiques de niveau recherche, publiés ou non, émanant des établissements d'enseignement et de recherche français ou étrangers, des laboratoires publics ou privés. 


\section{Author's Accepted Manuscript}

Patterned vegetation and rainfall intermittency

A.Y. Kletter, J. von Hardenberg, E. Meron, A. Provenzale

PII: $\quad$ S0022-5193(08)00561-4

DOI: $\quad$ doi:10.1016/j.jtbi.2008.10.020

Reference: $\quad$ YJTBI5345

To appear in: $\quad$ Journal of Theoretical Biology

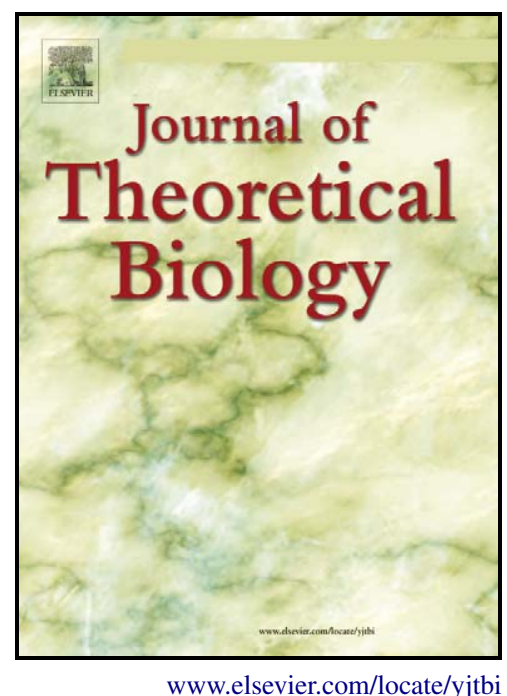

Received date: $\quad 30$ May 2008

Revised date: $\quad 1$ October 2008

Accepted date: $\quad 24$ October 2008

Cite this article as: A.Y. Kletter, J. von Hardenberg, E. Meron and A. Provenzale, Patterned vegetation and rainfall intermittency, Journal of Theoretical Biology (2008), doi:10.1016/j.jtbi.2008.10.020

This is a PDF file of an unedited manuscript that has been accepted for publication. As a service to our customers we are providing this early version of the manuscript. The manuscript will undergo copyediting, typesetting, and review of the resulting galley proof before it is published in its final citable form. Please note that during the production process errors may be discovered which could affect the content, and all legal disclaimers that apply to the journal pertain. 


\title{
Patterned vegetation and rainfall intermittency
}

\author{
A. Y. Kletter \\ Department of Physics, Ben Gurion University, Beer Sheva 84105, and \\ Department of Solar Energy and Environmental Physics, BIDR, Ben Gurion University, \\ Sede Boker Campus 84990, Israel \\ kletter@bgu.ac.il \\ J. von Hardenberg \\ Istituto di Scienze dell'Atmosfera e del Clima, \\ Consiglio Nazionale delle Ricerche, 73100 Lecce, Italy \\ j. vonhardenberg@isac.cnr.it \\ E. Meron \\ Department of Solar Energy and Environmental Physics, BIDR, \\ Ben Gurion University, Sede Boker Campus 84990, and \\ Department of Physics, Ben Gurion University, Beer Sheva 84105, Israel \\ ehud@bgu.ac.il \\ and \\ A. Provenzale (corresponding author) \\ Istituto di Scienze dell'Atmosfera e del Clima, \\ Consiglio Nazionale delle Ricerche, 10133 Torino, Italy \\ a.provenzale@isac.cnr.it
}

Received _ ; accepted 


\begin{abstract}
We study a mathematical model for the dynamics of patterned dryland vegetation in the presence of rainfall intermittency, adopting a spatially-explicit approach. We find that most results found for constant precipitation carry over to the case of intermittent rainfall, with a few important novelties. For intermittent precipitation, the functional forms of the water uptake and consequently of the vegetation growth rate play an important role. Nonlinear, concave-up forms of water uptake as a function of soil moisture lead to a beneficial effect of rainfall intermittency, with a stronger effect when vegetation feedbacks are absent. The results obtained with the explicit-space model employed here are in keeping with those provided by simpler, implicit-space approaches, and provide a more complete view of vegetation dynamics in arid ecosystems.
\end{abstract}

Subject headings: Vegetation dynamics, drylands, rainfall, ecosystem modeling, spatial-temporal patterns 


\section{Introduction}

Arid and semi-arid regions of the world are characterized by scarce, sporadic and strongly intermittent rainfall (Noy-Meir 1973, Chesson et al. 2004). In this hydrological regime, long periods of dry conditions are punctuated by short events of intense precipitation. In the highlands of the Negev Desert (Israel), for example, the total annual rainfall volume (typically below $200 \mathrm{~mm}$ ) usually comes in about ten to twenty individual events with duration of up to eight hours at most (Shanan et al. 1967).

Vegetation cover in arid and semi-arid regions is limited by water and nutrient availability, and it is highly sensitive to the temporal intermittency in rainfall (see e.g. Rodriguez-Iturbe and Porporato 2005, Katul et al. 2007). The sporadic occurrence of precipitation events leads to the presence of intermittent resource pulses, associated with the irregular alternance between short periods of abundant resource availability and long periods of high stress conditions. In this regime, the role of competition and facilitation can be very different from what happens under temporally constant conditions (e.g., Noy-Meir 1973, Goldberg and Novoplansky 1997, Gebauer et al. 2002, Chesson et al. 2004), and the susceptibility to invasion by exotic species can depend on the frequency and timing of the pulses (James et al. 2006). Analogous effects can be generated by stream flow intermittency on semiarid riparian vegetation (Stromberg et al. 2005).

Experimental observations indicate that rainfall intermittency in space and time usually plays a positive role for the survival of vegetation under water stress (Lundholm et al. 2004; Sher et al. 2004). One of the arguments used to rationalize this result is that intermittent rainfall leads to levels of soil moisture that are much higher, albeit only locally and for short times, than for constant precipitation. In addition, during a rainfall event the water infiltrating in the soil can easily reach deeper soil layers, where it is shielded from the intense evaporation that takes place close to the surface. 
Modelling studies of homogeneous vegetation cover in water-limited ecosystems revealed that the statistical properties of rainfall at intra-annual scale affect the probability distribution of soil moisture and evapotranspiration and thus determine the plant water stress (Laio et al. 2001; Porporato et al. 2001; Daly et al. 2004). Using an implicit-space approach, Baudena et al. (2007) showed that, for a fixed value of the total annual rainfall, the average fraction of soil covered by vegetation depends on the frequency of intense precipitation events. In turn, the statistical properties and the temporal variability of precipitation are expected to vary due to climate change (Katz and Brown 1992), possibly in the sense of increased intermittency. Owing to the sensitivity of the soil-vegetation system to the level of rainfall intermittency, these changes could significantly affect plant-soil-water interactions (Hillel 1998; Wainright et al. 1999; Porporato 2006).

In arid lands, however, vegetation cover is often characterized by the presence of spatial patterns such as spots, stripes and gaps, and spatial mixtures thereof (Valentin et al. 1999; von Hardenberg et al. 2001; Rietkerk et al. 2004; Barbier et al. 2006), which can make implicit-space approaches insufficient to describe the full spectrum of vegetation behavior. For this reason, in the past fifteen years spatial vegetation dynamics has been intensively studied by adopting various types of explicit-space approaches (Thiéry et al. 1995; Lefever and Lejeune 1997; Klausmeier 1999; HilleRisLambers et al. 2001; Okayasu and Aizawa 2001; von Hardenberg et al. 2001; Rietkerk et al. 2002; Shnerb et al 2003; Gilad et al. 2004; Meron et al. 2004; Rietkerk et al. 2004; Sherratt 2005; Yizhaq et al. 2005; Barbier et al. 2006; Gilad et al. 2007a; 2007b; Kefi et al. 2007; Sherratt and Lord 2007). Usually, modeling studies of the dynamics of patterned vegetation have considered either a constant, or a time-periodic rainfall input (Ursino and Contarini 2006; Guttal and Jayaprakash 2007; Sheffer et al. 2007), focusing on the effects of vegetation feedbacks such as differential infiltration, facilitation and competition. An important exception is the work of D'Odorico et al. (2006), who associated some of the pattern formation processes to random climatic 
fluctuations in rainfall.

Given the potential importance of rainfall intermittency, one may wonder whether the results found for constant rainfall carry over to the more realistic case of sporadic rainfall events. The present work is devoted to an exploration of this issue from an explicit-space modeling viewpoint. In particular, we study how rainfall intermittency affects the dynamics of patterned vegetation, and how an inhomogeneous vegetation cover responds to a temporally intermittent resource availability. Both issues are essential for properly modeling vegetation dynamics in arid ecosystems, owing to the ubiquitous presence of spatial vegetation patterning and the high sensitivity of the soil-plant system to temporal rainfall intermittency. None of these issues has been previously explored. As we discuss in detail below, the results indicate that vegetation dynamics in an intermittent rainfall regime is similar to what has been found for constant precipitation, with the additional beneficial effect of rainfall intermittency for nonlinear, concave-up forms of vegetation growth rates, according to Jensen's inequality (Ruel and Ayres 1999). Interestingly, the results found with the spatially-explicit model for vegetation dynamics used here are similar to those found with implicit-space approaches, paving the way to future comparisons between the two types of models.

The rest of this paper proceeds as follows. In Section 2 we discuss the explicit-space soil-vegetation model. Section 3 reports the results of the simulations, for different types of precipitation input. Section 4 is devoted to a detailed discussion of the results, and Section 5 provides summary and conclusions. 


\section{Soil-vegetation model}

The soil-vegetation model adopted here is based on a modification of the approach discussed by Gilad et al. (2004; 2007a). The model describes vegetation dynamics in a water-limited system and includes three state variables: above-ground biomass, $B$, in $\mathrm{kg} / \mathrm{m}^{2}$; average relative soil moisture, $s$, in the soil layer with depth $d$ meters containing the plants' roots; and water height above the soil surface, $H$. Water height is measured in millimeters, or equivalently, assuming water density to be $\rho_{w}=10^{3} \mathrm{~kg} / \mathrm{m}^{3}$, in $\mathrm{kg} / \mathrm{m}^{2}$. Relative soil moisture is defined as $s=W / W_{M A X}$ where $W$ is soil water density in $\mathrm{kg} / \mathrm{m}^{2}$ and $W_{M A X}$ is the saturation value of soil water in the layer considered, determined by $W_{M A X}=\rho_{w} n d$, where $n$ is soil porosity (Hillel 1998; Rodriguez-Iturbe and Porporato 2005). An important assumption of the model is that the main limiting factor for plant growth is water availability.

The system equations, in the case of a flat soil surface, are

$$
\begin{gathered}
\frac{\partial B}{\partial t}=G_{B}[s] B\left(1-\frac{B}{K}\right)-M B+D_{B} \nabla^{2} B \\
\frac{\partial s}{\partial t}=\frac{I H}{W_{M A X}}-\frac{N s}{1+R B / K}-G_{s}[B] \mathcal{F}(s)+D_{W} \nabla^{2} s \\
\frac{\partial H}{\partial t}=P-I H+D_{H} \nabla^{2}\left(H^{2}\right)
\end{gathered}
$$

where $t$ is time, $\mathbf{x}=(x, y)$ is space, and $\nabla^{2}=\partial^{2} / \partial x^{2}+\partial^{2} / \partial y^{2}$.

In the first equation, $G_{B}$ is the biomass growth rate per unit biomass, $K$ is the maximum standing biomass, $M$ is the mortality rate per unit biomass, and the diffusion term represents short-distance seed dispersal with diffusivity $D_{B}$.

The second equation determines the evolution of relative soil moisture; here $I H$ represents infiltration into the soil, $N s$ is evaporation from bare surfaces, and the last term on the right-hand-side (r.h.s.) measures soil-water diffusion with diffusivity $D_{W}$ (Hillel 
1998). The functional form $\mathcal{F}(s)$ is discussed in detail below. In the second equation we do not include a leakage term because we verified that even during the most intense rainfall events average soil moisture remains lower than soil field capacity, $s_{f c}$, defined as the value beyond which water is lost by gravitationally-induced leakage to lower layers (Hillel 1998). In the following, we take $s_{f c}=0.5$ and soil porosity $n=0.45$. Other choices in the physically reasonable range lead to qualitatively equivalent results.

In the third equation, $P$ is the precipitation rate, assumed either constant or variable in time but always homogeneous in space. The last term on the r.h.s. measures surface water redistribution due to runoff on the surface. This form of runoff is not simple diffusion of surface water and it can be obtained by assuming runoff water to be described as a shallow fluid layer in the lubrication approximation, see e.g. Gilad et al. (2004).

The model includes three main feedbacks, namely, the shading feedback, the infiltration feedback, and the water-uptake feedback, which are discussed in detail below (see Gilad et al. 2007a and D'Odorico et al 2007 for further details and Barbier et al. 2008 for quantitative estimates of these effects obtained in a semi-arid self-organized shrubland).

Shading feedback. Evaporation from vegetated soil is lower than from bare soil, owing to the shading effect of vegetation. This feedback is represented by the factor $1 /(1+R B / K)$, which reduces evaporation from the soil surface where $B \neq 0$. The increase in soil moisture below the plant contributes to an island of fertility under the plant canopy (Charley and West 1975; Ehrenfeld et al. 2005). If $R=0$, this feedback is absent.

Infiltration feedback. Infiltration is larger in vegetated areas than in bare areas, leading to larger values of soil moisture and contributing to the creation of an island of fertility below and around vegetation patches. This difference in infiltration is due to two main factors, 
(i) the presence of physical or biogenic crusts that reduce infiltration in bare soil (West 1990, Eldridge et al. 2002), and (ii) the fact that plant litter and soil mounds intercepting runoff and plant roots cracking the soil facilitate infiltration in vegetated areas (Shachak et al. 1998; Shachak and Lovett 1998; Bergkamp et al. 1999). This feedback is modeled by assuming the infiltration rate to be modulated by the presence of biomass (Walker et al. 1981; HilleRisLambers et al. 2001),

$$
I=A \frac{B(\mathbf{x}, t)+Q f}{B(\mathbf{x}, t)+Q}
$$

where $A, Q$ and $f$ are constant parameters. In bare soil, one has $I=A f$. In fully vegetated soil, $I \rightarrow A$. Thus, $f \leq 1$ measures the reduction of infiltration in bare soil compared to vegetated soil. The lower is $f$, the stronger is the infiltration feedback.

Water-uptake feedback. Larger plants have more extended root systems, enabling them to take up more soil water. The root-uptake feedback has two facets, one negative and one positive (Gilad et al. 2007a, Meron et al. 2007a). On one hand, larger plants lead to a stronger reduction of the water content at any given point in space, leaving less water for further biomass increase. On the other hand, there is a positive feedback which can be called a "root-augmentation" feedback. As the above-ground biomass grows, the root system extends in size and probes new regions. As a result, the amount of water available to the plant increases, which further increases the above-ground biomass.

These two effects are modeled by the forms of the vegetation growth rate, $G_{B}$, and of the water uptake from the soil, $G_{s}$. The vegetation growth rate is assumed to be an increasing function of the extension of the root system, which in turn is assumed to be proportional to the above-ground biomass. As a result, $G_{B}$ depends on the water uptake by the root system and it is modeled as

$$
G_{B}[s]=\Lambda_{M A X} \int G\left(\mathbf{x}, \mathbf{x}^{\prime}, t\right) \mathcal{F}\left(s\left(\mathbf{x}^{\prime}, t\right)\right) d \mathbf{x}^{\prime}
$$


where $\Lambda_{M A X}$ is the maximum biomass growth rate. In the soil water equation, the water uptake is assumed to depend on the root extent, and it is modeled as

$$
G_{s}[B]=\Gamma \int G\left(\mathbf{x}^{\prime}, \mathbf{x}, t\right) B\left(\mathbf{x}^{\prime}, t\right) d \mathbf{x}^{\prime}
$$

where $\Gamma$ measures soil water uptake per unit biomass.

Water uptake is described by nonlocal terms, owing to the spatial extension of the root system. The kernel $G$ represents the root system and it is given by

$$
G\left(\mathbf{x}, \mathbf{x}^{\prime}, t\right)=\frac{1}{2 \pi S_{0}} \exp \left[-\frac{\left|\mathbf{x}-\mathbf{x}^{\prime}\right|^{2}}{2\left[S_{0}(1+E B(\mathbf{x}, t))\right]^{2}}\right] .
$$

The parameter $S_{0}$ measures the minimum (linear) horizontal extent of the roots, while $E$ quantifies the root augmentation per unit biomass: The larger $E$, the stronger the feedback. This process introduces an important nonlinearity in the model, as the vegetation growth rate increases with biomass density. Analogously, water uptake at a point in space depends on all roots that reach that point. Note that $G\left(\mathbf{x}^{\prime}, \mathbf{x}, t\right) \neq G\left(\mathbf{x}, \mathbf{x}^{\prime}, t\right)$. Details on the numerical procedure adopted to compute the integral terms are given by Gilad and von Hardenberg (2006).

In the definition of $G_{B}$ and in the soil moisture equation, $\mathcal{F}(s)$ is the functional form of water uptake. In previous works (Gilad et al. 2004; 2007a), we always assumed a linear dependence of the water uptake, $\mathcal{F}(s)=C_{0} s$. In addition to this choice, here we explore the effects of a nonlinear, saturating form of water uptake, similar to a Holling type-III functional dependence (e.g., Holling 1966),

$$
\mathcal{F}(s)=\frac{C s^{4}}{1+\phi s^{4}}
$$

The form chosen here is characterized by a concave-up part at low values of soil moisture, and by a decelerating, concave-down part at larger values of soil moisture. This choice implies that at very low levels of soil moisture plants do not efficiently use water, while 
at very large soil moisture values plants cannot consume all the available water. Figure 1 shows the linear and the nonlinear forms of water uptake adopted in this work. The parameters $C_{0}, C$ and $\phi$ are fixed by requiring that, for both forms, $\mathcal{F}\left(s=s_{f c}\right)=1$ and that the bare state looses stability to the homogeneously vegetated state for the same value of annual precipitation.

The introduction of a saturating form of water uptake is motivated by the fact that during intense precipitation events, soil moisture can reach high values which cannot be fully exploited by the plants' roots. In addition, the functional form chosen here allows for studying the role of nonlinearities in the growth rate, which have been shown to play an important role in the case of implicit-space models (Baudena et al. 2007). In the Discussion, we also comment on another nonlinear functional form of the water uptake term, namely a Michaelis-Menten (Holling type-II) dependence (e.g., Kot 2001), characterized by a linear growth at low values of soil moisture and saturation at large soil moisture values. For a study of functional responses in arid ecosystems, see Chesson et al. (2004).

The model introduced above can be further simplified. Since the time scale of surface runoff is much faster than either the time scale of infiltration or of vegetation growth, we can assume that the surface water height adapts instantaneously to the precipitation input and discard the time derivative in the surface water equation. In this way, we obtain a diagnostic equation for $H$ :

$$
I H-D_{H} \nabla^{2}\left(H^{2}\right)=P
$$

With this approximation, the water height $H$ above the surface is non-zero only during a precipitation event when $P \neq 0$. Whenever $P=0$, the only solution is $H=0$.

In equation (2), the assumption of soil-water diffusion with a Laplacian term is a simplified one. In our model, however, soil water diffusion plays a secondary role as the main redistribution term for water comes from surface runoff, which is much faster than 
water diffusion within the soil. Another drawback of the model, which we accept here in order to keep the description simple, is that we assume a single layer of soil with a bucket-type hydrology. We do not explicitely model the propagation of the wetting front within the soil and we do not distinguish a surface shallow layer where evaporation takes place from a deeper layer where only plant roots consume water. Model experiments with an implicit-space model with multiple soil layers suggest that these assumptions do not lead to qualitative changes in the results with respect to bucket-type models (Baudena and Provenzale 2008). Future developments of the model discussed here should take into account the vertical structure of the soil.

\section{The role of rainfall intermittency}

To study the effects of rainfall intermittency on vegetation dynamics, we numerically integrate the model described above. Although its mathematical formulation is quite general and can be used for describing different vegetation life forms, here we consider a set of parameter values that are appropriate for the case of shrubs in drylands, with special attention to the conditions where shrubs act as ecosystem engineers (Jones et al. 1994; Gilad et al. 2004; 2007a; 2007b; Cuddington et al. 2007, Meron et al. 2007b). The study area is a square box with lateral size $L=5$ meters. The depth of the soil layer containing the plants' roots is assumed to be $d=3.5$ meters, consistent with observational results in arid regions (Canadell et al. 1996). Table 1 reports the values of the other model parameters, in accordance with those already employed in previous studies (Gilad et al. 2007a, Sheffer et al. 2007, Meron et al. 2007a and references therein).

Precipitation is either assumed to be constant in time, or to be intermittently distributed in a small number of intense events. The latter case is simulated by randomly positioning in time $N_{P}=12$ precipitation events per year, each event having duration of 
$T_{P}=8$ hours. The precipitation volume of each of these $N_{p}$ events is initially extracted from an exponential distribution (see e.g. Rodriguez-Iturbe and Porporato 2005). To avoid any differences in the total annual precipitation from one year to another, we repeat the same $N_{p}$ events in each year, varying only the randomly chosen time of their occurrence during the year. In this way, the total annual rainfall, obtained by adding the precipitation falling during each of the $N_{P}$ events, is the same in the different years.

For intermittent precipitation, we consider two cases: (i) the events are evenly distributed over the whole year; and (ii) rainfall events are concentrated in a period of 4 months that we call the "wet season". In this latter case, we include the effects of both rainfall intermittency and seasonality.

The first, interesting result is that the overall behavior of the system does not change much when passing from constant precipitation to intermittent rainfall. We observe the presence of spots, stripes and gaps, with the transition to denser patterns when annual rainfall increases. Of course, with intermittent precipitation there is no stationary state, and the whole system oscillates with the availability of water in correspondence of rainfall events. Figure 2 shows a snapshot of the spatial distribution of vegetation biomass, $B$, for constant precipitation (upper panels) and for intermittent precipitation without seasonality (lower panels), for a linear form (left panels) and for a type-III form of the water uptake $\mathcal{F}$ (right panels). In all cases, we have included a strong infiltration feedback, $f=0.1$. The annual precipitation has been fixed at $300 \mathrm{~mm} \mathrm{yr}^{-1}$, in the spot regime (Gilad et al. 2004; 2007a). Figure 3 shows the time evolution of the spatially-averaged biomass, $\langle B\rangle$, and of the fraction of area covered by vegetation, for the same cases. Here and in the following, we numerically integrate the coupled soil-vegetation system for 166 years. To be sure of having reached statistical stationarity, we discard the first half of the runs and compute statistical quantities only over the last 83 years of the simulation. For the purpose of quantifying the 
fraction of area covered by vegetation, the soil is considered to be occupied by vegetation if $B \geq 0.05 \mathrm{~kg} / \mathrm{m}^{2}$; note that, inside fully-developed spots, $B$ has a value of about $0.7 \mathrm{~kg} / \mathrm{m}^{2}$. The threshold value has been chosen consistently with our focus on shrubs; other choices of the threshold on $B$ lead to qualitatively analogous results (the exact value of the area fraction occupied by vegetation varying slightly with the threshold).

The curves of figure 3 indicate that the fraction of area covered by vegetation is larger for intermittent precipitation than for constant rainfall. For a type-III form of the water uptake, also the average biomass is larger in the case of intermittent precipitation. To test whether this behavior also holds for other rainfall rates, we show in Fig. 4 the average biomass and area coverage of vegetation as functions of the annual precipitation for strong infiltration feedback, for a linear form of $\mathcal{F}$ (panels a and c) and a type-III form (panels b and $d$ ). Panels a and b show the spatial average of biomass, and panels $c$ and $d$ show the

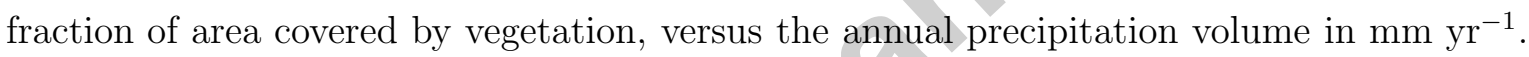
The three curves in each panel indicate the cases with constant precipitation, intermittent precipitation without seasonality and intermittent, seasonally-distributed rainfall.

When $\mathcal{F}$ is linear, there is a very small difference in average biomass and in vegetation cover for constant or intermittent (non-seasonal) precipitation, with a slight positive effect of intermittency at all values of annual rainfall for the fraction of area covered by vegetation and, at low values of annual rainfall, for the average biomass. On the other hand, seasonality and intermittency together have a detrimental effect on average biomass at larger values of annual rainfall.

The situation is rather different for the case of a nonlinear, concave-up form of $\mathcal{F}(s)$, as shown by the right panels in figure 4 . With this form of $\mathcal{F}$, the effect of rainfall intermittency is always beneficial to the average biomass and to the fraction of area covered by vegetation. In addition, vegetation can survive under harsher environmental conditions 
with rainfall intermittency. Note also that no substantial differences are observed between seasonal and non-seasonal intermittent rainfall, except for the response of the average biomass at high precipitation.

One cause of the behavior illustrated in figures $4 \mathrm{~b}, \mathrm{~d}$ is the chosen nonlinear form of the water uptake as a function of $s$ (and, indirectly, of precipitation), as discussed by Baudena et al. (2007) for implicit-space models. This is one more example of the application of Jensen's inequality in ecosystem dynamics (Ruel and Ayres 1999). This inequality simply states that the average nonlinear response to a fluctuating input depends on the sign of the second derivative of the response function. Although the explicit form of the growth rate in our model is complicated, we see that for intermittent precipitation $s$ also assumes intermittent values and, keeping for simplicity the biomass $B$ constant (since it has much slower variability), we can write that

$$
\overline{G_{B}[s]}=\Lambda_{M A X} \int G\left(\mathbf{x}, \mathbf{x}^{\prime}, t\right) \overline{\mathcal{F}\left(s\left(\mathbf{x}^{\prime}, t\right)\right)} d \mathbf{x}^{\prime}
$$

where the overbar denotes a time average. Then,

$$
\overline{\mathcal{F}(s)}=\overline{\mathcal{F}(\bar{s}+\delta s)} \approx \mathcal{F}(\bar{s})+\frac{1}{2}\left(\frac{d^{2} \mathcal{F}}{d s^{2}}\right)_{s=\bar{s}} \overline{(\delta s)^{2}}
$$

where $\delta s$ is the random fluctuation in soil moisture owing to rainfall intermittency and we have assumed $\overline{\delta s}=0$. For constant rainfall, $\delta s=0, s=\bar{s}$ and $\overline{\mathcal{F}(s)} \equiv \mathcal{F}(\bar{s})$. For intermittent rainfall, in the range where $\mathcal{F}$ is concave-up, $\left(d^{2} \mathcal{F} / d s^{2}\right)_{s=\bar{s}}>0$ and $\overline{\mathcal{F}(s)}>\mathcal{F}(\bar{s})$. For a nonlinear, concave-up form of $\mathcal{F}$, the time average of water uptake, $\overline{\mathcal{F}(s)}$, is thus larger than the water uptake for the average value of $s, \mathcal{F}(\bar{s})$. Since the biomass growth rate depends on water uptake, one then observes a larger effective growth rate for intermittent rain than for constant precipitation, provided that the average soil moisture is in the range where $\mathcal{F}$ is concave-up. For a linear $\mathcal{F}$, this effect is absent and the average biomass is basically the same for intermittent and for constant precipitation. 
On the other hand, figures $4 \mathrm{a}, \mathrm{c}$ show that even for a linear $\mathcal{F}$, the fraction of area covered by vegetation is slighty larger in the case of intermittent precipitation. The spatial variability of the surface water height during a precipitation event comes from the balance of differential infiltration, which tends to reduce $H$ where there is biomass, and the homogenizing effect of surface water redistribution by runoff. Surface runoff is more effective for larger values of $H$, owing to the smaller friction of the surface fluid layer with the ground. Thus, during the intense rainfall events of an intermittent precipitation regime, the value of $H$ grows large and the $H$ field becomes more homogeneous than for lower precipitation rates. This implies that $H$ can be larger in proximity of vegetation patches, with a beneficial effect for the biomass, especially at the edge of the spots. Overall, the total biomass remains approximately the same, but the spots become slightly larger and reach slightly smaller values of maximum biomass in their interior.

Soil moisture differences between vegetated and bare patches depend on the properties of the balance between infiltration (which is increased in proximity of vegetation) and water consumption. In bare patches, infiltration is lower and only evaporation takes place. In vegetated patches, infiltration is larger but water consumption is due to both evaporation and water uptake by plant roots. For most plants, the increase in infiltration and the shading effect are not enough to balance the larger water uptake associated with plant growth and evapotranspiration, and soil moisture becomes lower in vegetated patches than in bare soil. For some shrubs, however, in dry conditions the balance can become positive, evaporation can be reduced by shading effects, and the increase in infiltration is larger than that of water uptake (Gilad et al. 2004; 2007a; 2007b; Meron et al. 2007b). As a result, soil moisture becomes larger in vegetated areas than in bare soil, favouring the presence of other plant species (e.g., Callaway and Walker 1997; Maestre and Cortina 2004; Pugnaire and Luque 2006). This effect is an example of ecosystem engineering, a type of behavior where some living species modify the abiotic environment in ways that create habitats for 
other species, thereby affecting the whole community structure (Jones et al. 1994; 1997; Wright and Jones 2006; Cuddington et al. 2007).

One possible index of the intensity of the engineering effect is the ratio between the maximum soil moisture density below shrubs and the moisture in bare soil; if this ratio is larger than one, one can interpret the shrub action as ecosystem engineering. Figure 5 shows the ratio of maximum soil moisture in vegetated areas to the soil moisture in bare soil, for the linear (left) and type-III (right) functional forms of water uptake. For constant precipitation, the engineering effect disappears above about $150 \mathrm{~mm} / \mathrm{yr}$ for the linear uptake and above about $250 \mathrm{~mm} / \mathrm{yr}$ for the nonlinear form of $\mathcal{F}$. The effects of rainfall intermittency are different in the two cases: for a linear $\mathcal{F}$, intermittency does not have substantial effects, and at most it weakly increases the engineering effect. For the nonlinear, saturating form of $\mathcal{F}$, the engineering effect is significantly reduced in the presence of rainfall intermittency, and even more drastically so for seasonally-distributed intermittent precipitation events. This is due to the fact that, with this form of $\mathcal{F}$, for the same value of annual precipitation the total biomass is significantly larger for intermittent precipitation than for constant rainfall (see figure 4); consequently, the root systems and the corresponding water uptake are larger for intermittent rain and soil moisture in vegetated areas decreases.

In a previous work with implicit-space models (Baudena and Provenzale 2008), it was shown that the effects of rainfall intermittency on vegetation survival are larger in the absence of vegetation feedbacks. To explore whether this is true also for the explicit-space model adopted here, we have studied the case with $f=1$, i.e., without infiltration feedback. Figure 6 shows the results for the case with no infiltration feedback, $f=1$, for the linear form of $\mathcal{F}$ (panels a and c) and the type-III form (panels b and d). As before, panels a and $\mathrm{b}$ show the spatial average of biomass, $\langle B\rangle$, and panels $\mathrm{c}$ and $\mathrm{d}$ show the fraction of area 


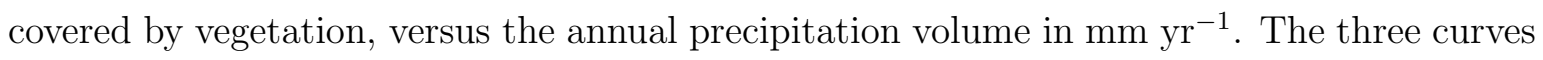
in each panel indicate the cases with constant precipitation, intermittent precipitation without seasonality and intermittent, seasonally-distributed rainfall.

Without infiltration feedback, precipitation intermittency has a strong effect for a type-III form of $\mathcal{F}$, allowing for vegetation persistence at values of annual rainfall well below those required for the survival of vegetation in the case of constant precipitation. Comparing figures $4 \mathrm{~b}, \mathrm{~d}$ with figures $6 \mathrm{~b}, \mathrm{~d}$, we see that the effect of rainfall intermittency is stronger when there is no infiltration feedback. The overall effect of eliminating the infiltration feedback is to decrease the ability of the vegetation to survive at low rainfall rates. However, rainfall intermittency helps counterbalancing this effect significantly.

The beneficial effect of precipitation intermittency vanishes with a linear form of $\mathcal{F}$, and becomes detrimental to vegetation especially at high precipitation rates. With a linear $\mathcal{F}$, there is no advantage coming from averaging the vegetation growth rate on widely different values of soil moisture (as instead happens for the nonlinear, concave-up form of $\mathcal{F}$ ). Further, the joint effects of long periods of dry conditions (during which evaporation is strong) and of the lack of infiltration feedback lead to lower values of soil moisture in vegetated areas and ultimately to lower biomass. In the case of seasonally-distributed precipitation, the long dry periods last long enough to lead to a significant reduction in the model biomass and, consequently, to a reduction in water uptake with a further detrimental effect on vegetation.

\section{Discussion}

The exploration of the dynamics of the spatially-explicit model introduced above has revealed that the basic qualitative aspects of vegetation dynamics in the case of constant 
precipitation are similar to those for intermittently-distributed rainfall, providing confidence in the results obtained so far with the analysis of spatially-explicit vegetation models with constant precipitation input.

In addition, the results reported here indicate that precipitation intermittency can favour vegetation persistence and survival, in keeping with experimental observations of vegetation dynamics under water stress (Lundholm et al. 2004; Sher et al. 2004). Usually, the beneficial effect of rainfall intermittency is ascribed to the fact that during episodic, intense rainfall events some water infiltrates below the layer where rapid evaporation takes place, and it can then be used by plants during later dry periods. This mechanism is absent in our model as we do not explicitely distinguish between a surface layer with strong evaporation and a lower layer where water does not evaporate. The results obtained with this model indicate that another mechanism can be active, namely, the nonlinear response of vegetation to water availability and resource pulses.

In the following, we discuss in some details this point and some of the related issues.

\subsection{Jensen's inequality and the beneficial effect of a concave-up water uptake term}

As shown in figures 4 and 6 , in the model adopted here precipitation intermittency does not necessarily play a positive role for vegetation persistence, unless the vegetation growth rate is a nonlinear, concave-up function of soil moisture (and thus of precipitation intensity). As discussed above, this is one more example of the relevance of Jensen's inequality in ecosystem dynamics (Ruel and Ayres 1999).

For a concave-up form of water uptake, the average growth rate for intermittent precipitation is larger than the growth rate corresponding to the average (or constant) 
precipitation, and vegetation survival is enhanced. As a consequence, plants can survive in drier conditions than for constant precipitation. In addition, for any given value of annual rainfall both the biomass and the fraction of vegetated surface are larger than for constant precipitation.

In keeping with Jensen's inequality, vegetation is negatively affected by precipitation intermittency in the case of a concave-down form of the growth rate. In this case, in fact, $\left(d^{2} \mathcal{F} / d s^{2}\right)_{s=\bar{s}}<0$ and $\overline{\mathcal{F}(s)}<\mathcal{F}(\bar{s})$. Simulations with a type-II (or Michaelis-Menten) form of the growth rate, $\mathcal{F}(s)=C^{\prime} s /\left(1+\phi^{\prime} s\right)$, reveal that in this case, as expected, rainfall intermittency is detrimental to vegetation, and both the average biomass and the fractional vegetation cover are lower than for constant precipitation.

\subsection{Ecosystem engineering}

As illustrated in figure 5, for a type-III response form rainfall intermittency leads to a reduction of the engineering capacity of the shrubs. In general, shrubs become ecosystem engineers when the enhanced infiltration and reduced evaporation due to shading associated with the presence of vegetation dominate the water uptake by the root system, and lead to soil-moisture concentration under the shrub patch. In the case of a concave-up response form, however, rainfall intermittency can tilt the water balance under a shrub patch towards water uptake, by increasing the biomass growth rate and consequently the spatial extension of the root system. Intermittent rainfall can therefore decrease the engineering capacity of shrubs. Note that the effect of reduced engineering is weaker at higher rainfall rates where the response form is no longer concave up. 


\subsection{The role of vegetation feedbacks}

The work of Baudena and Provenzale (2008) on implicit-space models of vegetation dynamics has indicated that the beneficial effect of rainfall intermittency for a concave-up vegetation growth rate is larger in the absence of shading and infiltration feedbacks. We explored the same issue in the fully explicit spatial model studied here, obtaining similar results. Figures 4 and 6 show respectively a case with strong infiltration feedback $(f=0.1)$ and a case without infiltration feedback $(f=1)$. We found that for a type-III water uptake form, with and without feedbacks, the presence of rainfall intermittency is always beneficial to vegetation. However, the effect is stronger in the absence of infiltration feedback. We can thus speculate that in the presence of intermittent rainfall, vegetation has at least two strategies for enhancing its survival: either evolve the ability to setup and use the infiltration feedback, e.g. by producing litter, and/or evolve a concave-up form of the dependence of the intensity of the water uptake on soil moisture. This second option should be favored in dry areas with limited crust cover. Field and laboratory measurements and manipulation experiments could provide more insight into these issues.

\subsection{The role of seasonality}

Seasonality in the precipitation regime can have important effects on dryland vegetation dynamics (Ursino and Contarini 2006; Guttal and Jayaprakash 2007; Sheffer et al. 2007). We explored the role of seasonality in the case of intermittent rainfall, assuming the precipitation events to be either uniformly spread over the whole year (no seasonality), or concentrated in a wet season with duration of four months, with no rainfall during the dry season. For a strong infiltration feedback $(f=0.1$, see figure 4$)$, there is no significant difference between the seasonal and non-seasonal intermittent precipitation regimes for the fraction of area covered by vegetation and, at low annual precipitation, for the average 
biomass. Only at larger values of the annual precipitation, the average biomass is lower for the seasonal than for the non-seasonal case. No qualitative difference was found between the linear and the type-III response forms.

Differences between the two forms of water uptake are instead observed for the engineering effect, as illustrated in figure 5. For a linear form of water uptake, there is hardly any difference between the seasonal and non-seasonal regimes of intermittent rainfall. For a type-III water uptake form ecosystem engineering is significantly reduced by rainfall intermittency, especially in the case of seasonally-distributed, intermittent precipitation. As discussed above, this reduction of the engineering effect is due to the larger biomass obtained in this case.

In the absence of infiltration feedback (see figure 6), the role of seasonality becomes more evident. For a linear form of water uptake, intermittency and seasonal intermittency are always detrimental to vegetation, even more so for larger values of annual precipitation. For seasonally-distributed precipitation, the time scale of precipitation variability is comparable to that of biomass mortality. During dry periods, plant biomass decreases due to mortality and small growth rates associated with low soil humidity. As a result, the overall extent of the active root systems (assumed to be proportional to the biomass) becomes smaller, ${ }^{1}$ leading to further reduction of the water uptake and to still smaller biomass growth rates. At large values of annual precipitation, the effect of seasonal

\footnotetext{
${ }^{1}$ This should not be interpreted in the sense of a reduction of the roots' extension in dry periods, but rather as a reduction of the active root biomass by mortality of the corresponding plants. In this model, we do not describe the behavior of individual plants but rather the above-ground biomass at a certain location, and assume below-ground biomass to be proportional to above-ground biomass. We did not include any hysteresis in the relationship between above- and below-ground biomass or plasticity of the root system.
} 
intermittency are more evident, because the root-uptake feedback is stronger (at low values of precipitation, the root length is bounded from below by $S_{0}$ and relative variations are smaller). The larger rainfall intensity during wet periods does not compensate for dry periods, owing to the $1-B / K$ factor in the nonlinear growth rate which becomes important at high precipitation rates, where the growth is $K$-limited rather than limited by soil moisture. The detrimental role of seasonality is especially evident for a linear form of the water uptake term $\mathcal{F}$, since in this case rainfall intermittency has little or no beneficial effect. By contrast, for a nonlinear, concave-up form of water uptake, seasonal intermittency is beneficial especially at low values of annual precipitation because the nonlinearity in the water-uptake part of the growth rate dominates over the root-length feedback. In the presence of a strong infiltration feedback $(f=0.1$, figure 4$)$, one observes similar results, even though the role of rainfall intermittency is always reduced in this case.

\section{Conclusions}

In this work we have studied the properties of a spatially-extended model for dryland vegetation exposed to intermittent precipitation. The main qualitative aspects of vegetation dynamics obtained for constant precipitation, such as the existence of patterned states and the role of shrubs as ecosystem engineers, carry over to the case of intermittent rainfall.

Rainfall intermittency is beneficial to vegetation in the case of a nonlinear, concave-up form of the water uptake term and thus of the biomass growth rate. For a linear growth rate, intermittency does not play any significant role at low rainfall rates. In the absence of infiltration feedback, the effects of rainfall intermittency are stronger than for the case of an active infiltration feedback.

The results obtained here with a fully spatially-explicit vegetation model are similar 
to what has been found with implicit-space models (Baudena et al. 2007; Baudena and Provenzale 2008). Both types of models capture some of the basic aspects of vegetation dynamics and of soil-vegetation-climate interactions, suggesting that the bulk properties of patterned vegetation states can be approximately described by simpler models where spatial dependence is treated implicitely. This can be especially interesting in the context of climatic studies where the space and time scales involved often require the use of simple, parameterized models, and one must take into account the feedback of vegetation and soil moisture dynamics on atmospheric motions (Entekhabi et al. 1992; D'Andrea et al. 2006; Dekker et al. 2007).

From an ecological standpoint, the results reported in this paper indicate that the form of the water uptake, and consequently of the vegetation growth rate, is important in determining vegetation survival and the vegetation response to intermittent resource pulses. The beneficial effects of a concave-up water uptake form is stronger in the absence of significant vegetation feedbacks such as differential infiltration, indicating that the two effects are not fully cumulative.

We thank Mara Baudena for careful reading of this manuscript and for useful comments. We thank Erez Gilad, Yonatan Natan, Moshe Shachak and Hezi Yizhaq for useful comments and for interesting discussions. This study has been supported by the James S. McDonnell Foundation and by the Center for Complexity Science. 


\section{REFERENCES}

Barbier, N., Couteron, P., Lejoly, J., Deblauwe, V., Lejeune, O., 2006. Self-organized vegetation patterning as a fingerprint of climate and human impact on semi-arid ecosystems. J. Ecology 94, 537-547.

Barbier, N., Couteron, P., Lefever, R., Deblauwe, V., Lejeune, O., 2008. Spatial decoupling of facilitation and competition at the origin of gap vegetation patterns in SW Niger. Ecology 89, 1521-1531.

Baudena, M., Boni, G., Ferraris, L., von Hardenberg, J., Provenzale, A., 2007. Vegetation response to rainfall intermittency in drylands: Results from a simple ecohydrological box model. Advances in Water Resources 30, 1320-1328.

Baudena, M., Provenzale, A., 2008. Rainfall intermittency and vegetation feedbacks in drylands. Hydrology and Earth System Science. 12, 679-689.

Bergkamp G., Cerda, A., Imeson, A.C., 1999. Magnitude-frequency analysis of water redistribution along a climate gradient in Spain. Catena 37, 129-146.

Callaway, R.M., Walker L.R., 1997. Competition and facilitation: A synthetic approach to interactions in plant communities. Ecology 78, 1958-1965.

Canadell, J., Jackson, R.B., Ehleringer, J.B., Mooney, H.A., Sala, O.E., Schulze E.-D., 1996. Maximum rooting depth of vegetation types at the global scale. Oecologia 108, 583-595.

Charley, J., West, N., 1975. Plant-induced soil chemical patterns in some shrub-dominated semi-desert ecosystems in Utah. J. Ecology 63, 945-963.

Chesson, P., Gebauer, R.L.E., Sher, A., Schwinning, S., Wiegand, K., Ernest, M.S.K., Huntly, N., Novoplansky, A., Weltzin, J.F., 2004. Resource pulses, species 
interactions, and diversity maintenance in arid and semi-arid environments. Oecologia 141, 236-253.

Cuddington, K., Byers, J.E., Wilson, W.G., Hastings, A., Eds., 2007. Ecosystem Engineers: Plants to Protists. Academic Press, Burlington.

Daly, E., Porporato, A., Rodriguez-Iturbe, I., 2004. Coupled dynamics of photosynthesis, transpiration, and soil water balance. Part II: Stochastic analysys and ecohydrological significance. J. Hydrometeorology 5, 559-566.

D'Andrea, F., Provenzale, A., Vautard, R., de Noblet-Ducoudré, N., 2006. Hot and cool summers: Multiple equilibria of the continental water cycle. Geophys. Res. Lett. 33, L24807.

Dekker, S.C., Rietkerk, M., Bierkens, M.F.P., 2007. Coupling microscale vegetation soil water and macroscale vegetation precipitation feedbacks in semiarid ecosystems. Global Change Biol. 13, 671-678.

D’Odorico, P., Laio, F., Ridolfi, L., 2006. Vegetation patterns induced by random climatic fluctuations. Geophys. Res. Letters 33, L19404.

D’Odorico, P., Caylor, K., Okin, G.S., Scanlon, T.M., 2007. On soil moisture-vegetation feedbacks and their possible effects on the dynamics of dryland ecosystems. Journal of Geophysical Research-Biogeosciences 112, G04010.

Ehrenfeld, J.G., Ravit, B., Elgersma, K., 2005. Feedback in the plant-soil system. Ann. Rev. Environment Resources 30, 75-115.

Eldridge, D.J., Zaady, E., Shachak, M., 2002. Microphytic crusts, shrub patches and water harvesting in the Negev Desert: The Shikim system. Landscape Ecology 17, 587-597. 
Entekhabi, D., Rodriguez-Iturbe, I., Bras, R.L., 1992. Variability in large-scale water balance with land surface-atmosphere interaction. J. Climate 5, 798-813.

Gebauer, R.L.E., Schwinning, S., Ehleringer, J.R., 2002. Interspecific competition and resource pulse utilization in a cold desert community. Ecology 83, 2602-2616.

Gilad, E., von Hardenberg, J., Provenzale, A., Shachak, M., Meron, E., 2004. Ecosystem engineers: from pattern formation to habitat creation. Phys. Rev. Letters 93, 0981051.

Gilad, E., von Hardenberg, J., 2006. A fast algorithm for convolution integrals with space and time variant kernels. J. Comput. Physics 216, 326-336.

Gilad, E., von Hardenberg, J., Provenzale, A., Shachak, M., Meron, E., 2007a. A mathematical model of plants as ecosystem engineers. J. Theoretical Biology 244, 680-691.

Gilad, E., Shachak, M., Meron, E., 2007b. Dynamics and spatial organization of plant communities in water-limited systems. Theor. Pop. Biol. 72, 214-230.

Goldberg, D., Novoplansky, A., 1997. On the relative importance of competition in unproductive environments. J. Ecology 85, 409-418.

Guttal, V., Jayaprakash, C., 2007. Self-organization and productivity in semi-arid ecosystems: Implications of seasonality in rainfall. J. Theoretical Biol. 248, 490-500.

Hillel, D., 1998. Environmental Soil Physics. Academic Press, San Diego.

HilleRisLambers, R., Rietkerk, M., Van den Bosch, F., Prins, H.H.T., de Kroon, H., 2001. Vegetation pattern formation in semi-arid grazing systems. Ecology 82, 50-61.

Holling, C.S., 1966. The functional response of invertebrate predators to prey density. Mem. Entomol. Soc. Canada 48, 1-86. 
James, J.J., Caird, M.A., Drenovsky, R.E., Sheley, R.L., 2006. Influence of resource pulses and perennial neighbors on the establishment of an invasive annual grass in the Mojave desert. Current Biology 3, 528-534.

Jones, C.G., Lawton, J.H., Shachak, M., 1994. Organisms as ecosystem engineers. Oikos 69, 373-386.

Jones, C.G., Lawton, J.H., Shachak, M., 1997. Positive and negative effects of organisms as ecosystem engineers. Ecology 78, 1946-1957.

Katul, G., Porporato, A., Oren, R., 2007. Stochastic dynamics of plant-water interactions. Ann. Rev. Ecology, Evolution, and Systematics 38, 767-791.

Katz, R.W., Brown, B.G., 1992. Extreme events in a changing climate: varibility is more important than averages. Climatic Change 21, 289-302.

Kefi, S., Rietkerk, M., Alados, C.L., Pueyo, Y., Papanastasis, A.P., ElAich, A., de Ruiter, P.C., 2007. Spatial vegetation patterns and imminent desertification in Mediterranean arid ecosystems. Nature 449, doi:10.1038/nature06111.

Klausmeier, C.A., 1999. Regular and irregular patterns in semiarid vegetation. Science 284, $1826-1828$.

Kot, M., 2001. Elements of Mathematical Ecology. Cambridge University Press, Cambridge.

Laio F., Porporato, A., Fernandez-Illescas, C.P., Rodriguez-Iturbe, I., 2001. Plants in water controlled ecosystems: active role in hydrological processes and response to water stress IV. Discussion of real cases. Adv. Water Res. 24, 745-762.

Lefever, R., Lejeune, O., 1997. On the origin of the tiger bush. Bull. Math. Biol. 59, 263-294.

Levins, R., 1969. Some demographic and genetic consequences of environmental heterogeneity for biological control. Bull. Entomol. Soc. Am. 15, 237-240. 
Lundholm, J.T., Larson, D.W., 2004. Experimental separation of resource quantity from temporal variability: seedling responses to water pulses. Oecologia 141, 346-352.

Maestre, F.T., Cortina, J., 2004. Do positive interactions increase with abiotic stress? A test from a semiarid steppe. Proc. R. Soc. London B (Suppl.) 271, S331-S333.

Meron, E., Gilad, E., von Hardenberg, J., Shachak, M., Zarmi, Y., 2004. Vegetation patterns along a rainfall gradient. Chaos, Solitons and Fractals 19, 367-376.

Meron, E., Yizhaq, H., Gilad, E., 2007a. Localized structures in dryland vegetation: forms and functions. CHAOS 17, 037109.

Meron, E., Gilad, E., von Hardenberg, J., Provenzale, A., Shachak, M., 2007b. Model studies of ecosystem engineering in plant communities. In: K. Cuddington, Byers, J.E., Wilson, W.G., Hastings A. (Eds.), Ecosystem Engineers: Plants to Protists. Academic Press, Burlington, pp.229-251.

Noy-Meir, I., 1973. Desert ecosystems: environment and producers. Ann. Rev. Ecology Systematics 4, 25-51.

Okayasu, T., Aizawa Y., 2001. Systematic analysis of periodic vegetation patterns. Prog. Theor. Phys. 106, 705-720.

Porporato, A., Laio, F., Ridolfi, L., Rodriguez-Iturbe, I., 2001. Plants in water controlled ecosystems: active role in hydrological processes an response to water stress III. Vegetation water stress. Adv. Water Res. 24, 725-744.

Porporato, A., Vico, G., Fay, P., 2006. Superstatistics of hydro-climatic fluctuations and interannual ecosystem productivity. Geophys. Res. Lett. 33, L15402.

Pugnaire, F.I., Luque, M.T., 2006. Changes of plant interactions along a gradient of environmental stress. Oikos 93, 42-29. 
Rietkerk, M., Boerlijst, M.C., van Langevelde, F., HilleRisLambers, R., van de Koppel, J., Kumar, L., Prins, H.H.T., De Roos, A.M., 2002. Self-organization of vegetation in arid ecosystems. Am. Nat. 160, 524-530.

Rietkerk, M., Dekker, S.C., de Ruiter, P.C., van de Koppel, J., 2004. Self-organized patchiness and catastrophic shifts in ecosystems. Science 305, 1926-1929.

Rodriguez-Iturbe, I., Porporato, A., 2005. Ecohydrology of water controlled ecosystems: soil moisture and plant dynamics. Cambridge University Press, Cambridge, UK.

Ruel, J.J., Ayres, M.P., 1999. Jensen's inequality predicts the effects of environmental variation. Trens Ecol. Evol. 14, 361-366.

Shachak, M., Sachs, M., Moshe, I., 1998. Ecosystem Management of Desertified Shrublands in Israel. Ecosystems 1, 475-483.

Shachak, M., Lovett, G.M., 1998. Atmospheric deposition to a desert ecosystem and its implications for management. Ecological Applications 8, 455-463.

Shanan, L., Evenari, M., Tadmor, N.H., 1967. Rainfall patterns in the Central Negev desert. Isr. Explor. J. 17, 163-184.

Sheffer, E., Yizhaq, H., Gilad, E., Shachak, M., Meron, E., 2007. Why do plants in resource deprived environments form rings? Ecological Complexity 4, 192-200.

Sher, A.A., Goldberg, D.E., Novoplansky, A., 2004. The effect of mean and variance in resource supply on survival of annuals from Mediterranean and desert environments. Oecologia 141, 353-362.

Sherratt, J.A., 2005. An analysis of vegetation stripe formation in semi-arid landscapes. J. Math. Biology 51, 183-197. 
Sherratt, J.A., Lord, G.J., 2007. Nonlinear dynamics and pattern bifurcations in a model for vegetation stripes in semi-arid environments. Theor. Population Biol. 71, 1-11.

Shnerb, N.M., Sarah, P., Lavee, H., Solomon, S., 2003. Reactive Glass and vegetation patterns. Phys. Rev. Lett. 90, 0381011.

Stromberg, J.C., Bagstad, K.J., Leenhouts, J.M., Lite, S.J., Makings, E., 2005. Effects of stream flow intermittency on riparian vegetation of a semiarid region river (San Pedro River, Arizona). River Research and Applications 21, 925-938.

Tilman, D., 1994. Competition and biodiversity in spatially-structured habitats. Ecology $75,2-16$.

Thiéry, J.M., d'Herbés, J.M., Valentin, C., 1995. A model simulating the genesis of banded vegetation patterns in Niger. J. Ecology 83, 497-507.

Ursino, N., Contarini, S., 2006. Stability of banded vegetation patterns under seasonal rainfall and limited soil moisture storage capacity. Adv. Water Res. 29, 1556-1564.

Valentin, C., d'Herbés, J.M., Poesen, J., 1999. Soil and water components of banded vegetation patterns. Catena 37, 1-24.

von Hardenberg, J., Meron, E., Shachak, M., Zarmi, Y., 2001. Diversity of vegetation patterns and desertification. Phys. Rev. Letters 87, 198101.

Yizhaq, H., Gilad, E., Meron, E., 2005. Banded vegetation: biological productivity and resilience. Physica A 356, 139-144.

Wainright, J., Mulligan, M., Thornes, J., 1999. Plants and water in drylands. In: Baird, A.J., Wilby, R.R. (Eds.), Eco-hydrology: Plants and Water in Terrestrial and Aquatic Environments. Routledge, London, pp. 78-126. 
Walker, B.H., Ludwig, D., Holling, C.S., Peterman, R.M., 1981. Stability of semi-arid savanna grazing systems. J. Ecol. 69, 473-498.

West, N.E., 1990. Structure and function in microphytic soil crusts in wildland ecosystems of arid and semi-arid regions. Adv. Ecol. Res. 20, 179-223.

Wright, J.P., Jones, C.G., 2006. The concept of organisms as ecosystem engineers ten years on: Progress, limitations, and challenges. BioScience 56, 203-209.

This manuscript was prepared with the AAS LATEX macros v5.2. 


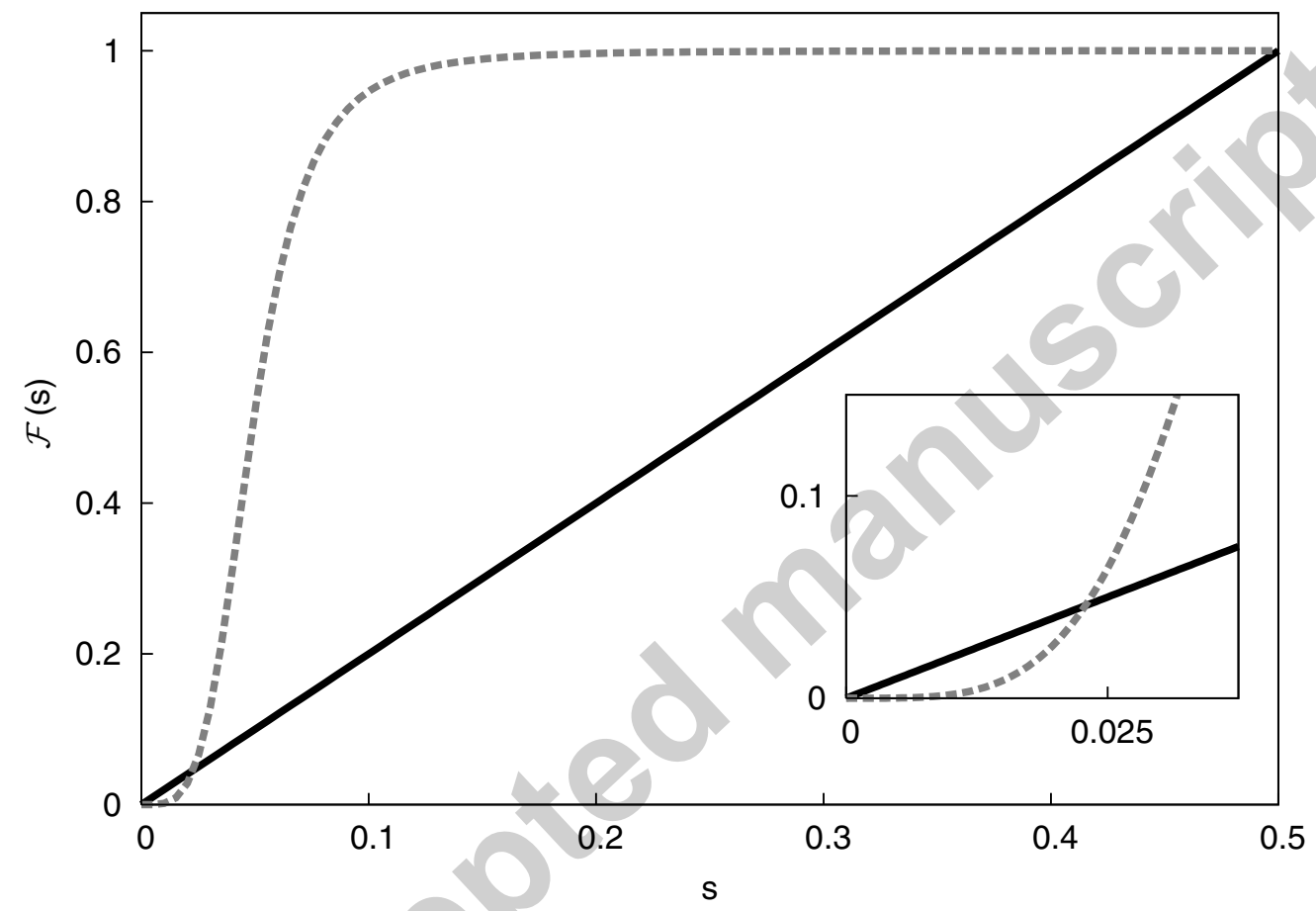

Fig. 1. - Functional forms of the water uptake term, $\mathcal{F}(s)$ where $s=W / W_{M A X}$, adopted in this work. The inset shows an enlargment of the region for small $s$. 


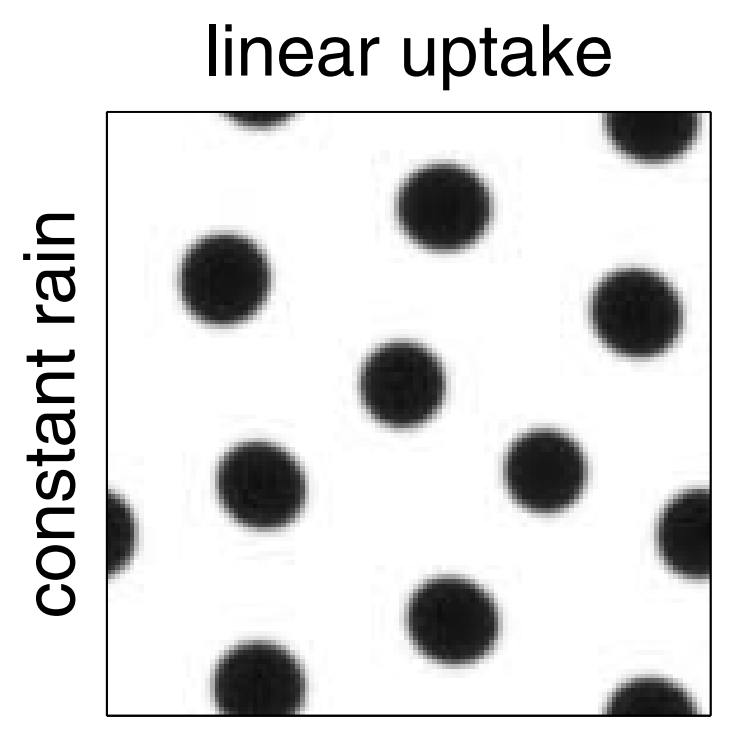

\section{type 3 uptake}
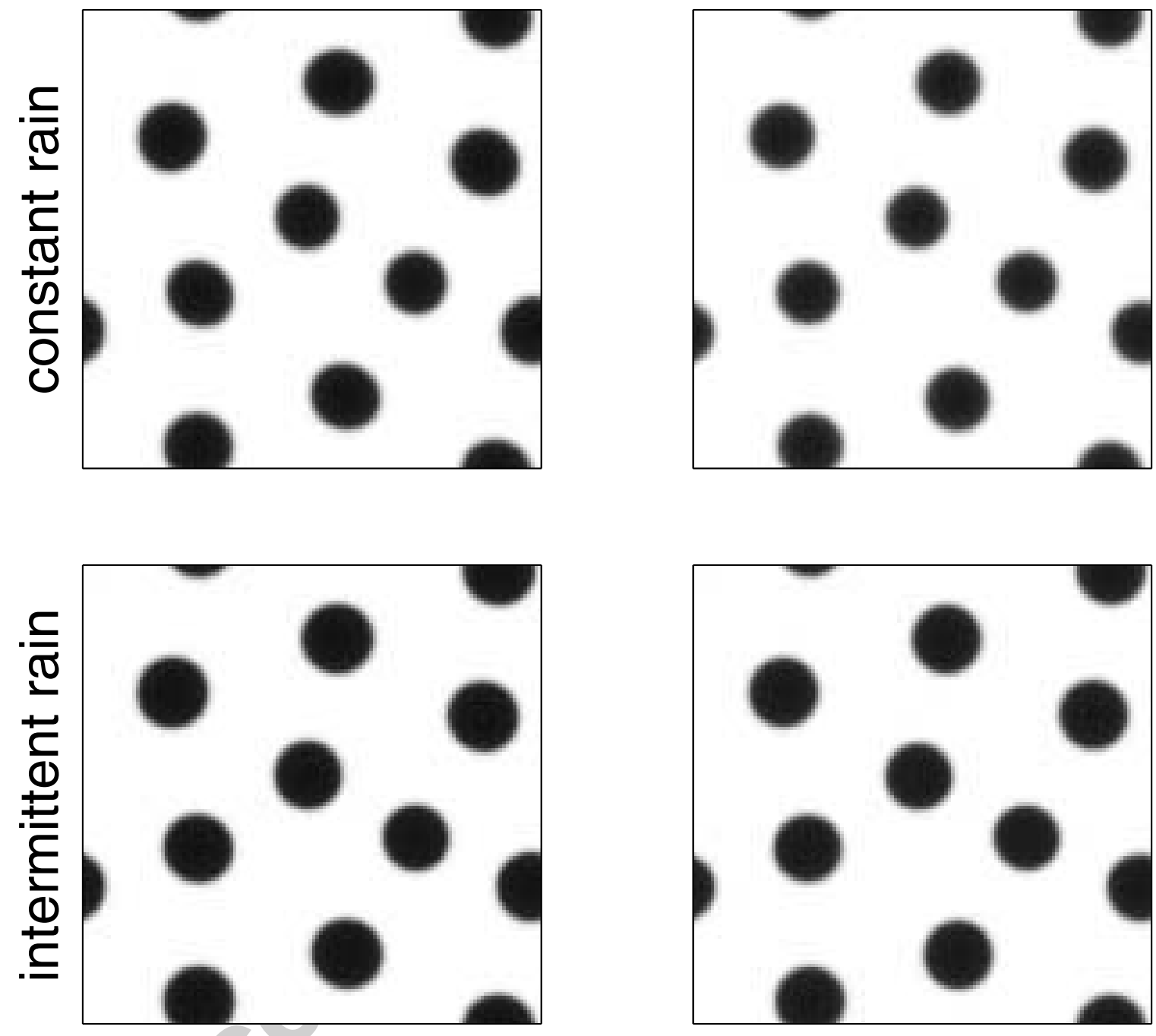

Fig. 2.- Snapshot of the spatial distribution of biomass, for constant precipitation (upper panels), and intermittent rainfall without seasonality (lower panels), at the end of a 166-yr long integration of the model. Left panels refer to the case with linear functional response, $\mathcal{F}$, and right panels to the case of a type-III form of $\mathcal{F}$. In all cases, $f=0.1$ and the annual

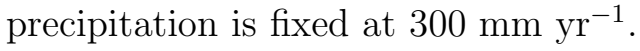



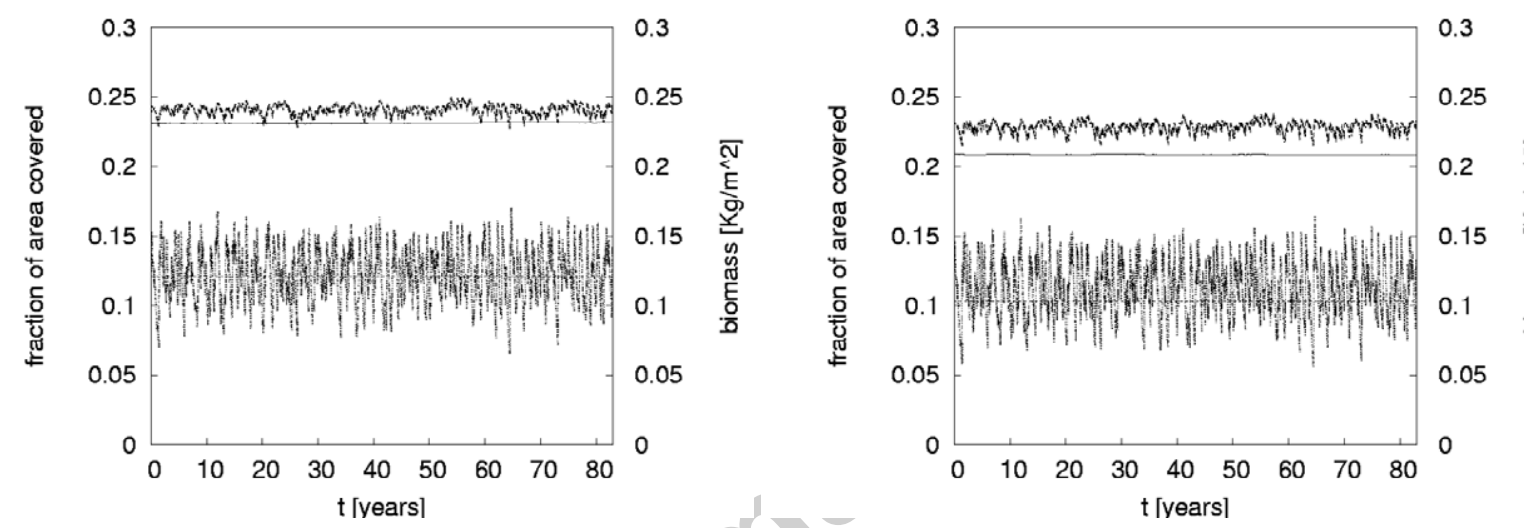

Fig. 3.- Time evolution of the fraction of area covered by vegetation (upper curves) and of the spatially-averaged biomass in $\mathrm{kg} / \mathrm{m}^{2}$ (lower curves). The straight lines refer to the case of constant precipitation, the fluctuating curves to the case of intermittent precipitation without seasonality. The left panel is for a linear form of $\mathcal{F}$, the right panel for a type-III form of $\mathcal{F}$. In all cases, $f=0.1$ and the annual precipitation is fixed at $300 \mathrm{~mm} \mathrm{yr}^{-1}$. 
a)

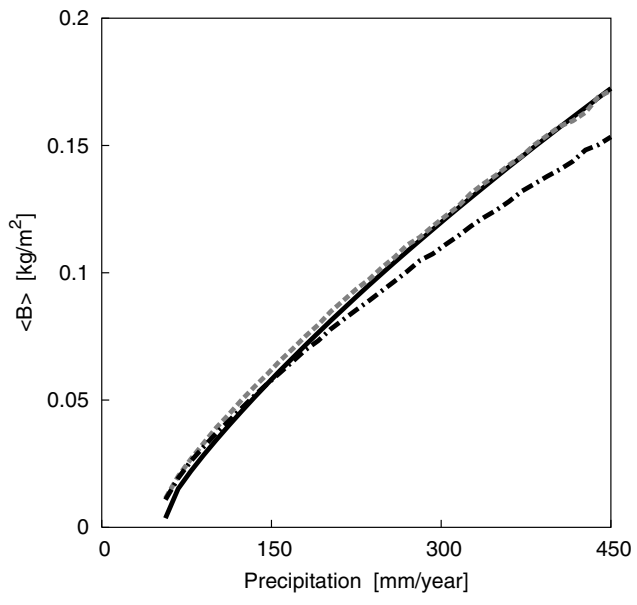

c)

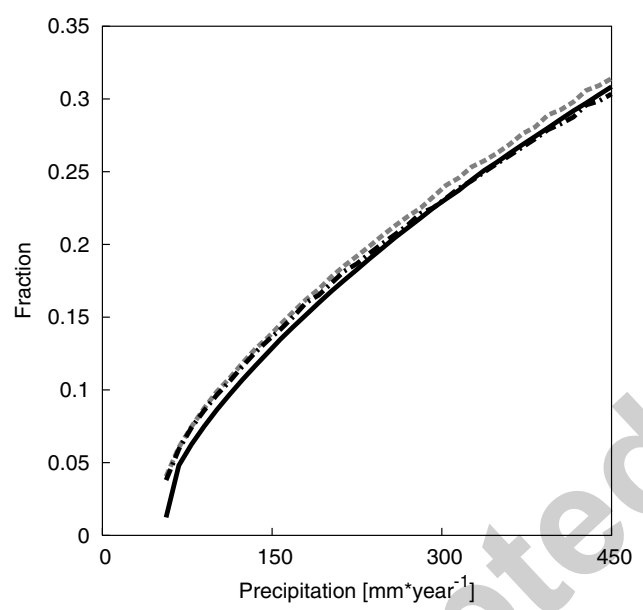

b)

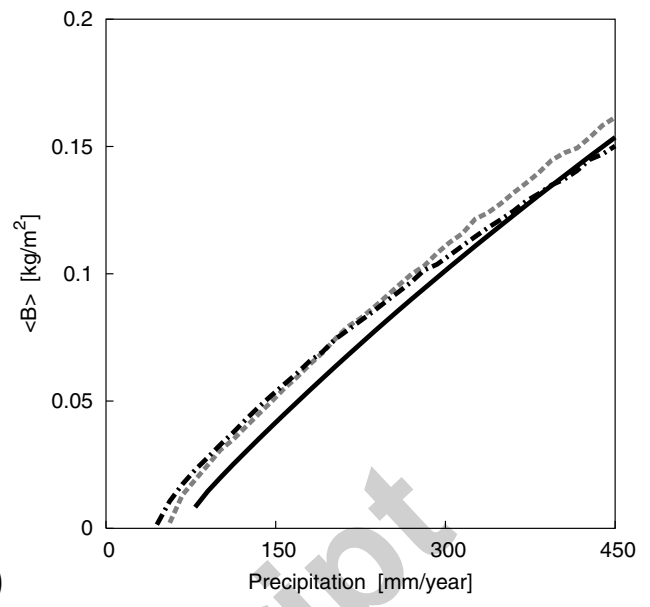

d)

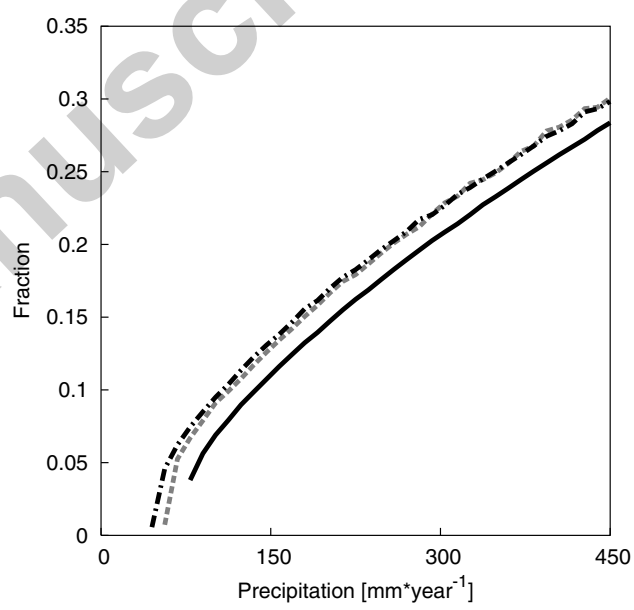

Fig. 4. - Value of the spatial average of biomass, $\langle B\rangle$ (panels a,b), and of the fraction of soil surface covered by vegetation (panels c,d) as functions of the annual precipitation volume in $\mathrm{mm} \mathrm{yr}^{-1}$. Panels a and $\mathrm{c}$ refer to a linear form of the water uptake term $\mathcal{F}(s)$, panels $\mathrm{b}$ and d to a type-III form of $\mathcal{F}(s)$. In each panel, the solid curve refers to constant precipitation, the dashed line to intermittent precipitation without seasonality and the dash-dotted line to seasonally-distributed, intermittent precipitation. For all cases, $f=0.1$. 

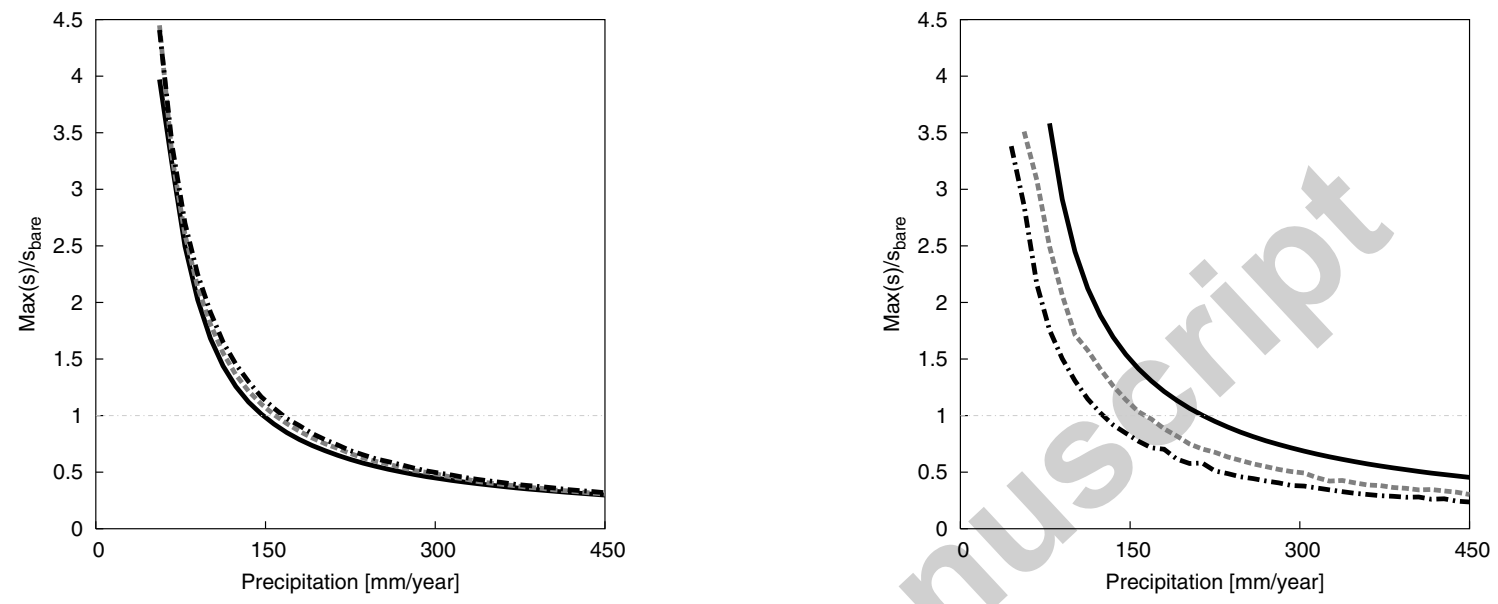

Fig. 5.- Ratio between the maximum soil moisture value in vegetated areas, Max $(s)$, and the soil moisture in bare soil, $s_{\text {bare }}$, as functions of annual precipitation. This ratio provides a measure of the engineering effect of the shrubs. The left panel refers to a linear form of the water uptake term $\mathcal{F}(s)$, the right panel to a type-III form of $\mathcal{F}(s)$. In each panel, the solid curve refers to constant precipitation, the dashed line to intermittent precipitation without seasonality and the dash-dotted line to seasonally-distributed, intermittent precipitation. For all cases, $f=0.1$. 
a)

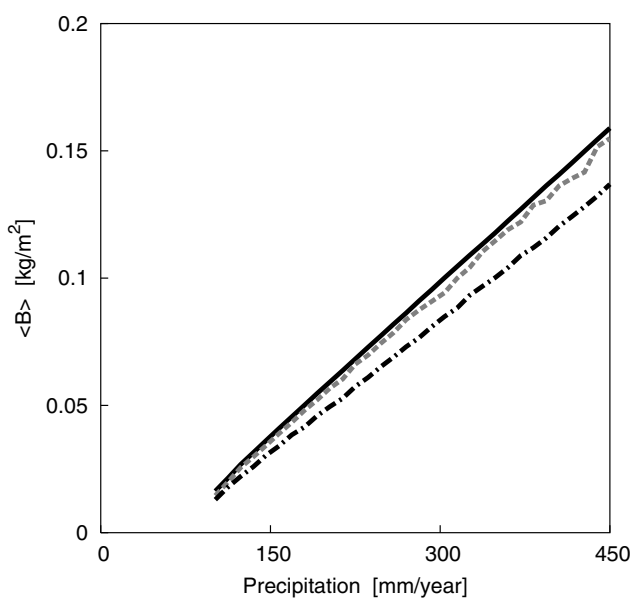

c)

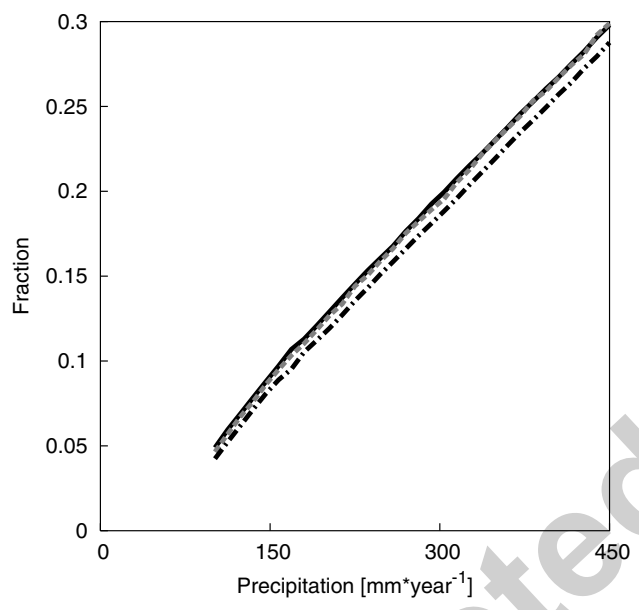

b)

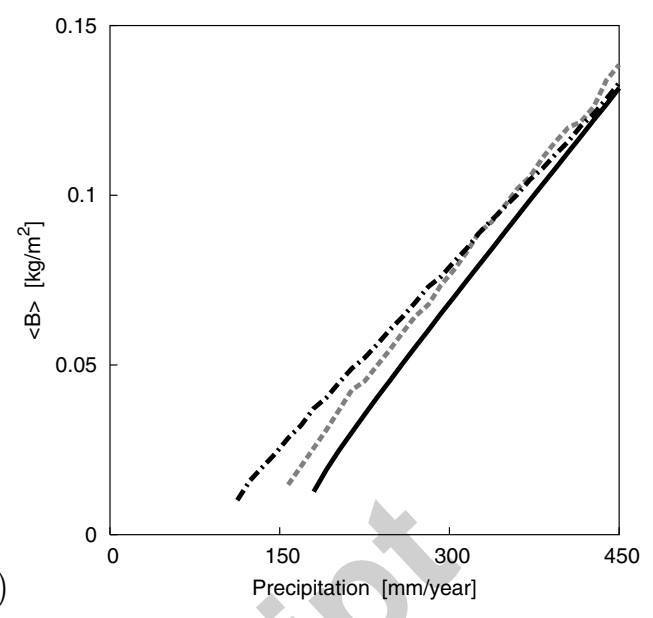

d)

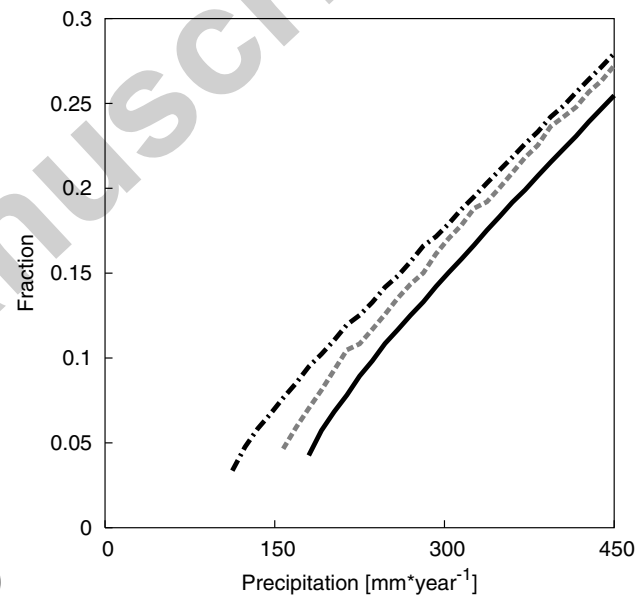

Fig. 6. - Value of the spatial average of biomass (panels a,b) and of the fraction of soil surface covered by vegetation (panels c,d) as functions of the annual precipitation volume in

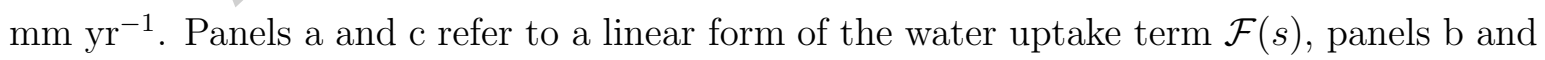
d to a type-III form of $\mathcal{F}(s)$. In each panel, the solid curve refers to constant precipitation, the dashed line to intermittent precipitation without seasonality and the dash-dotted line to seasonally-distributed, intermittent precipitation. For all cases, there is no infiltration feedback, $f=1$. 
Table 1: List of model parameters and of their values. The chosen values are appropriate for shrubs.

\begin{tabular}{|c|c|c|c|}
\hline Symbol & Meaning & Value & Units \\
\hline$L$ & Lateral size of the domain & 5 & $\mathrm{~m}$ \\
\hline$d$ & Depth of the soil layer & 3.5 & $\mathrm{~m}$ \\
\hline$n$ & Soil porosity & 0.45 & - \\
\hline$W_{M A X}$ & $\begin{array}{l}\text { Saturation water density in the soil } \\
\text { layer }\end{array}$ & 1600 & $\mathrm{~kg} / \mathrm{m}^{2}$ \\
\hline$K$ & Maximum standing biomass & 1 & $\mathrm{~kg} / \mathrm{m}^{2}$ \\
\hline$M$ & Mortality rate & 1.2 & $\mathrm{yr}^{-1}$ \\
\hline$A$ & Infiltration rate in fully vegetated soil & 1200 & $\mathrm{yr}^{-1}$ \\
\hline$Q$ & $\begin{array}{l}\text { Reference value beyond which infil- } \\
\text { tration reaches its maximum }\end{array}$ & 0.05 & $\mathrm{~kg} / \mathrm{m}^{2}$ \\
\hline$N$ & Evaporation rate & 6 & $\mathrm{yr}^{-1}$ \\
\hline$E$ & $\begin{array}{l}\text { Roots' augmentation per unit } \\
\text { biomass point }\end{array}$ & 3.5 & $\left(\mathrm{~kg} / \mathrm{m}^{2}\right)^{-1}$ \\
\hline$S_{0}$ & Minimal root system's size & 0.125 & $\mathrm{~m}$ \\
\hline$\Lambda_{M A X}$ & Maximum biomass growth rate & 25.6 & $\mathrm{yr}^{-1}$ \\
\hline$\Gamma$ & $\begin{array}{l}\text { Soil water uptake rate per unit } \\
\text { biomass }\end{array}$ & 10 & $\mathrm{~kg} / \mathrm{m}^{2} \mathrm{yr}^{-1}$ \\
\hline$D_{B}$ & Seed dispersal coefficient & $6.25 \times 10^{-4}$ & $\mathrm{~m}^{2} / \mathrm{yr}$ \\
\hline$D_{W}$ & Soil moisture diffusivity & $6.25 \times 10^{-2}$ & $\mathrm{~m}^{2} / \mathrm{yr}$ \\
\hline$D_{H}$ & $\begin{array}{l}\text { Coefficient of above-ground water re- } \\
\text { distribution }\end{array}$ & 100 & $\mathrm{~m}^{2} / \mathrm{yr}\left(\mathrm{kg} / \mathrm{m}^{2}\right)^{-1}$ \\
\hline$R$ & Evaporation reduction due to shading & 10 & - \\
\hline$f$ & $\begin{array}{l}\text { Infiltration contrast beween bare and } \\
\text { vegetated soil }\end{array}$ & $0.1-1$ & - \\
\hline
\end{tabular}

